\title{
EDITORIAL
}

\section{In This Issue: \\ Practice Change and Patient Safety}

\author{
Kurt C. Stange, $M D, P b D$, Editor \\ Ann Fam Med 2004;2:290-292. DOI: 10.1370/afm.218.
}

I $\mathrm{n}$ this issue we present a large series of articles on the related topics of practice quality improvement and patient safety. This issue also features an updated recommendation from the US Preventive Services Task Force, 2 timely studies-one of seasonal interest and another of political timeliness and clinical importance-as well as additional studies of clinical interest.

\section{PRACTICE CHANGE FOR QUALITY IMPROVEMENT}

The randomized clinical trial by Roetzheim and colleagues ${ }^{1}$ shows that an office systems intervention can be effective in increasing cancer preventive service delivery in primary care clinics serving disadvantaged populations. The online appendixes for this article provide additional intervention details, cost-effectiveness, and secondary analysis details for the interested reader.

Also in this issue, 2 large national intervention trials for mental health depict important frameworks for understanding the process of practice change. Dietrich and his colleagues from the MacArthur Foundation RESPECT-Depression trial report a broadly applicable, evidence-based clinical model of depression care. ${ }^{2}$ In an online appendix and related links, they present a depression management toolkit, information on project design and practice change strategies, and details on the clinical model for depression management. The study by Gallo and colleagues ${ }^{3}$ reports early findings from the PRIME-E clinical trial of integrating behavioral health care into primary care settings. They find that participating clinicians report a preference for integrated mental health care, compared with referral care, as providing better care in multiple dimensions.

\section{PATIENT SAFETY}

The related cluster of papers on medical errors and patient safety begins with a model that seems to contradict to the current zeitgeist, which attributes patient safety almost entirely to systems solutions. ${ }^{4}$ The rational-emotive model proposed by Borrell-Carrio and colleagues ${ }^{5}$ actually provides a much-needed complement to the current systems obsession by showing how emotional self-awareness and self-regulation of attention can be consciously cultivated to improve our function as clinicians. The other important studies in this cluster on patient safety call for a complementary systems approach. ${ }^{6-8}$ These articles are groundbreaking in developing new methods for studying medical errors in outpatient practice, and in giving us novel and helpful ways of conceptualizing the problem and potential solutions. They identify the importance of breakdowns in access and relationships ${ }^{8}$ and help us to understand errors as a cascade with multiple precipitants and therefore multiple potential intervention points. ${ }^{6}$

\section{TIMELY TOPICS AND CLINICAL RESEARCH}

As summer comes into full swing in the northern hemisphere, the study by Ramsey et $\mathrm{al}^{9}$ reminds us of the need to be selective in our approach to diagnosing and treating Lyme disease, and provides evidence of factors, such as patient demand, that affect appropriate test ordering.

The study by Karasz and colleagues ${ }^{10}$ is timely for a different reason. The recent FDA decision to reject over-the-counter sale of morning-after contraception $^{11,12}$ is brought into stark relief by the barriers to emergency contraception identified by these researchers. Using ethnographic methods, they examined the use of advance prescriptions for emergency contraception-a strategy intended to increase access in settings in which over-the-counter availability does not exist. The findings identify trade-offs between access and reservations held by both clinicians and patients.

Hypothyroidism is associated with abnormalities in cholesterol. This finding has been used as a justification for screening for subclinical hypothyroidism. The study by Hueston and colleagues ${ }^{13}$ finds, however, that 
subclinical hypothyroidism is not associated with lipid abnormalities in a large nationally representative sample.

The study by McCord et al ${ }^{14}$ finds that most patients want clinicians to ask about spiritual beliefs, and identifies specific situations in which patients want their clinicians to ask. Patients in this study also identify the potential benefits of this knowledge for their health care.

The US Preventive Services Task Force recommendation ${ }^{15}$ for syphilis screening in high-risk populations and pregnant women and against screening of asymptomatic persons not at increased risk shows the importance of a relationship context and knowing the patient for optimizing preventive service delivery.

An essay by Gianakos ${ }^{16}$ provides a very human view of noncompliance and the understanding that can develop between a patient and physician with time.

\section{INFORMATION FOR AUTHORS}

Revised information for authors is now available at the Annals Web site. ${ }^{17}$

The submission of so many excellent manuscripts resulted in our developing a backlog of accepted papers. We are happy to report that the queue has been reduced. Although time to publication can vary, a typical manuscript accepted now will be published within the next 3 issues. On occasion, the editors expedite the postacceptance process for particularly time-sensitive manuscripts for which early publication enhances impact.

Two articles in this issue of the Annals show the power of a journal that combines both print and online components. These articles by Roetzheim ${ }^{1}$ and by Dietrich $^{2}$ and their colleagues serve as models for how to portray succinctly the essence of a complicated clinical study while using online-only appendixes for depicting important additional information. We believe that a tightly focused main manuscript has the greatest potential to engage a wide audience of readers. Appendixes provide an excellent opportunity to portray additional detail or to explore related topics that are of interest to experts or to those who have become engaged by the shorter paper. We encourage authors to consider writing short manuscripts and using appendixes to portray supplemental material succinctly when doing so suits the topic. Additional details are given in the revised information for authors.

\section{A NEW ANNALS FEATURE}

One of the goals of the Annals is to make new medical knowledge available to a wide range of people. To that end, we are pleased to introduce a feature called In Brief.
In Brief provides a concise overview of each article in nontechnical language. We hope that all readers, including patients, health care professionals, policy makers, and others in the general public, will find this informative, and that it will encourage you to participate in the online TRACK discussion of articles. There are 3 ways to access In Brief: on the Annals home page at http:// www.annfammed.org, where you can click on The Issue In Brief button (beneath Current Issue); or click on the link that accompanies each article; or click on Current Issue and on The Issue In Brief at the top of the page.

To read or post commentaries in response to this article, see it online at http://www.annfammed.org/cgi/content/full/2/4/290.

\section{References}

1. Roetzheim RG, Christman LK, Jacobsen PB, et al. A randomized controlled trial to increase cancer screening among attendees of community health centers. Ann Fam Med. 2004;2:294-300.

2. Dietrich AJ, Oxman TE, Williams JW, et al. Going to scale: re-engineering systems for primary care treatment of depression. Ann Fam Med. 2004;2:301-304.

3. Gallo JJ, Zubritsky C, Maxwell J, et al. Primary care providers evaluate integrated and referral models of behavioral health care for older adults: results from a multisite effectiveness trial (PRISM-E). Ann Fam Med. 2004;2:305-309.

4. Wasson JH. Why isn't it better? Ann Fam Med. 2004;2:292-293.

5. Borrell-Carrió F, Epstein RM. Preventing errors in clinical practice: a call for self-awareness. Ann Fam Med. 2004;2:310-316.

6. Woolf SH, Kuzel AJ, Dovey SM, Phillips RL, Jr. A string of mistakes: the importance of cascade analysis in describing, counting, and preventing medical errors. Ann Fam Med. 2004;2:317-326.

7. Fernald DH, Pace WD, Harris DM, West DR, Main DS, Westfall JM. Event reporting to a primary care patient safety reporting system: a report from the ASIPS Collaborative. Ann Fam Med. 2004;2:327-332.

8. Kuzel AJ, Woolf SH, Gilchrist VJ, et al. Patient reports of preventable problems and harms in primary health care. Ann Fam Med. 2004:2:333-340.

9. Ramsey AH, Belongia EA, Chyou P-H, Davis JP. Use and appropriateness of Lyme disease serologic testing. Ann Fam Med. 2004;2:341344.

10. Karasz A, Kirchen NT, Gold M. The visit before the morning after: barriers to preprescribing emergency contraception. Ann Fam Med. 2004;2:345-350.

11. Galson S. Letter regarding supplemental drug application. Available at: http://www.fda.gov/cder/drug/infopage/planB/planB_NALetter.pdf.

12. FDA press release. Available at: http://www.fda.gov/bbs/topics/ news/2004/NEW01064.html.

13. Hueston WJ, Pearson WS. Subclinical hypothyroidism and the risk of hypercholesterolemia. Ann Fam Med. 2004;2:351-355.

14. McCord G, Gilchrist VJ, Grossman SD, et al. Discussing spirituality with patients: a rational and ethical approach. Ann Fam Med. 2004;2:356-361.

15. US Preventive Services Task Force. Screening for syphilis infection: recommendation statement. Ann Fam Med. 2004;2:362-365.

16. Gianakos D. Pounds. Ann Fam Med. 2004;2:366-367.

17. Annals of Family Medicine Web site. Information for authors. Available at http://www.annfammed.org/misc/ifora.shtml. 